\title{
Clustering of dietary intake and sedentary behavior in 2-year-old children.
}

Citation for published version (APA):

Gubbels, J. S., Kremers, S. P., Stafleu, A., Dagnelie, P. C., de Vries, S. I., de Vries, N. K., \& Thijs, C. (2009). Clustering of dietary intake and sedentary behavior in 2-year-old children. Journal of Pediatrics, 155(2), 194-198. https://doi.org/10.1016/j.jpeds.2009.02.027

Document status and date:

Published: 01/01/2009

DOI:

10.1016/j.jpeds.2009.02.027

Document Version:

Publisher's PDF, also known as Version of record

Document license:

Taverne

Please check the document version of this publication:

- A submitted manuscript is the version of the article upon submission and before peer-review. There can be important differences between the submitted version and the official published version of record.

People interested in the research are advised to contact the author for the final version of the publication, or visit the DOI to the publisher's website.

- The final author version and the galley proof are versions of the publication after peer review.

- The final published version features the final layout of the paper including the volume, issue and page numbers.

Link to publication

\footnotetext{
General rights rights.

- You may freely distribute the URL identifying the publication in the public portal. please follow below link for the End User Agreement:

www.umlib.nl/taverne-license

Take down policy

If you believe that this document breaches copyright please contact us at:

repository@maastrichtuniversity.nl

providing details and we will investigate your claim.
}

Copyright and moral rights for the publications made accessible in the public portal are retained by the authors and/or other copyright owners and it is a condition of accessing publications that users recognise and abide by the legal requirements associated with these

- Users may download and print one copy of any publication from the public portal for the purpose of private study or research.

- You may not further distribute the material or use it for any profit-making activity or commercial gain

If the publication is distributed under the terms of Article $25 \mathrm{fa}$ of the Dutch Copyright Act, indicated by the "Taverne" license above, 


\title{
Clustering of Dietary Intake and Sedentary Behavior in 2-Year-Old Children
}

\author{
Jessica S. Gubbels, MSc, Stef P. J. Kremers, PhD, Annette Stafleu, PhD, Pieter C. Dagnelie, MD, PhD, Sanne I. de Vries, MSc,
} Nanne K. de Vries, PhD, and Carel Thijs, MD, PhD

Objective To examine clustering of energy balance-related behaviors (EBRBs) in young children. This is crucial because lifestyle habits are formed at an early age and track in later life. This study is the first to examine EBRB clustering in children as young as 2 years.

Study design Cross-sectional data originated from the Child, Parent and Health: Lifestyle and Genetic Constitution (KOALA) Birth Cohort Study. Parents of 2578 2-year-old children completed a questionnaire. Correlation analyses, principal component analyses, and linear regression analyses were performed to examine clustering of EBRBs.

Results We found modest but consistent correlations in EBRBs. Two clusters emerged: a "sedentary-snacking cluster" and a "fiber cluster." Television viewing clustered with computer use and unhealthy dietary behaviors. Children who frequently consumed vegetables also consumed fruit and brown bread more often and white bread less often. Lower maternal education and maternal obesity were associated with high scores on the sedentary-snacking cluster, whereas higher educational level was associated with high fiber cluster scores.

Conclusions Obesity-prone behavioral clusters are already visible in 2-year-old children and are related to maternal characteristics. The findings suggest that obesity prevention should apply an integrated approach to physical activity and dietary intake in early childhood. (J Pediatr 2009;155:194-8).

everal studies have examined the co-occurrence, or "clustering," of energy balance-related behaviors (EBRBs). Clustering is defined as a combination of behaviors that is more prevalent than expected on the basis of the prevalence of the separate behaviours. ${ }^{1}$ The potential synergy between EBRBs could be used in obesity prevention interventions, applying an integrated approach in which multiple EBRBs are addressed simultaneously. Furthermore, by identifying behavioral clusters, high-risk groups can be identified.

Evidence for the clustering of EBRBs in 7- to 18-year-old children and adolescents is extensive. However, little is known about EBRB clustering in children younger than 7 years. DuRant et al observed 3- and 4-year-old children and found an inverse correlation between television viewing and time spent being physically active. ${ }^{2}$ Dietary clusters were found in 2- to 3-year-old children from low-income families and in 4-year-old children, reflecting behavioral combinations that contribute either positively or negatively to the energy balance., ${ }^{3,4}$ Only 1 study has examined clustering in young children across dietary intake and physical activity. ${ }^{5}$ This study reported $2 \mathrm{EBRB}$ clusters in 3- to 6-year-old children: 1 characterized by high levels of physical activity and varied food intake, and 1 characterized by sedentary and snacking behavior. However, as yet it is unclear whether these clusters already exist in even younger children.

The aim of this study was to examine EBRB clustering in 2-year-old children. We hypothesized that EBRBs contributing to a positive energy balance are already clustered at the age of 2 years, both within and across behavioral domains.

\section{Methods}

The Child, Parent and Health: Lifestyle and Genetic Constitution (KOALA) Birth Cohort Study, The Netherlands, is a prospective cohort study that started in 2000. Pregnant women were partially recruited from an existing cohort on pregnancy-related pelvic girdle pain and partially through alternative channels. ${ }^{6}$ All participants gave informed consent, and ethical approval was obtained from the Maastricht University/University Hospital Maastricht medical ethics

\footnotetext{
BMI Body mass index

EBRBs Energy balance-related behaviors

KOALA Child, Parent and Health: Lifestyle and Genetic Constitution (in Dutch)

TV Television
}

From the Department of Health Promotion, NUTRIM School for Nutrition, Toxicology and Metabolism, Maastricht University Medical Centre, Maastricht, The Netherlands (J.G., S.K., N.dV.); TNO Quality of Life, Leiden/Zeist, the Netherlands (A.S., S.dV.); and Department of Epidemiology,NUTRIM School for Nutrition, Toxicology and Metabolism, and School for Public Health and Primary Care (CAPHRI), Maastricht University Medical Centre, Maastricht, The Netherlands (P.D., C.T.)

The study was financially supported by the Triodos Foundation, Royal Friesland Foods, University Hospital Maastricht, and funds unrelated to commercial organizations (Iona Foundation, Phoenix Foundation, Foundation for the Advancement of Heilpedagogiek). J.G. is financed by the NUTRIM School for Nutrition, Toxicology and Metabolism, Maastricht University Medical Centre. and Metabolism, Maastricht University Med.
The authors declare no conflicts of interest.

0022-3476/\$ - see front matter. Copyright ( 2009 Mosby Inc. All rights reserved. 10.1016/j.jpeds.2009.02.027 
committee. In total, 2834 women completed questionnaires during pregnancy and regularly after birth. Questionnaires about 2578 2-year-old children were returned (91.0\%). In all, $51.2 \%$ of the children were male, and more than half the children (58.5\%) attended daycare. The age of the mother during pregnancy ranged from 17 to 45 years (mean, 32 years), and the country of birth was in most cases the Netherlands $(96.5 \%)$. A total of $48.7 \%$ of the mothers had a high education level, $37.6 \%$ a medium education level, and $13.7 \%$ a low education level. A total of $17.9 \%$ of the mothers were recruited through alternative channels and had alternative lifestyles for dietary habits (eg, vegetarian, organic), child rearing, vaccination schemes, or antibiotics use.

When the children reached the age of 2 years, the parents (mostly mothers) completed a questionnaire about their child's EBRBs during the preceding month (ie, including both weekdays and weekend days). The following activity behaviors were assessed: television (TV) viewing, computer use, and playing outside. TV viewing was measured by asking, "How much time does your child spend watching television/videos?" The response categories were: "My child does not watch television/videos," "Up to 15 minutes per day," "15-60 minutes per day," "1-2 hours per day," and "More than 2 hours per day." Computer use was assessed with a similar item, whereas playing outside was measured with 2 questions. The first was "Does your child play outside? (Yes/No) If yes, how often?” (Daily/once every two days/1-2 times per week/rarely). The second was "How long does your child play outside on those occasions?" (Less than 1 hour at a time/1-2 hours at a time/more than 2 hours at a time).

Dietary intake was assessed by asking parents how often their child consumed 13 food items: brown bread (including both whole-wheat bread and brown bread), white bread, raw vegetables, cooked vegetables, fresh fruit, squash concentrate, soft drinks with little or no sugar (light), other soft drinks, chocolate milk, chocolate, cookies and pastry, chips and other salty snacks and sweets. Response categories were: "never," "less than once per week," "1-3 times per week," "4-6 times per week," "once per day," "twice per day," "3 times per day," and "more than 3 times per day." Portion size was not assessed. Cooked and raw vegetables were combined in 1 variable representing total vegetable intake frequency. Cookies, chocolate, chips, and sweets were aggregated to represent total snack intake frequency. Finally, squash concentrate, sugarsweetened soft drinks, and chocolate milk were combined to represent total sugar-sweetened beverage intake. This category was solely based on sugar content of the drinks.

All activity behavior items were re-coded into average minutes per day, and the food variables were re-coded into average daily intake frequency. For answer categories that comprised a range of response possibilities, the midpoint value of the category was used for further calculation. For example, the category of watching 1 to 2 hours of TV a day was translated into 90 minutes a day and multiplied by the frequency of the behavior to calculate the total number of minutes per week, which was then divided by 7 to calculate the average per day.
Parents were asked to report the weight and height of the child as assessed at his/her periodic screening at an infant welfare center at age 2 years. Weight and height were used to calculate the child's body mass index (BMI; ie, weight/[height $]^{2}$ in $\mathrm{m} / \mathrm{kg}^{2}$ ). Because of variations in measurement dates at the infant welfare centers, BMI was only calculated for children who visited these centers between the age of 22 and 26 months (ie, 24 months \pm 2 months). Because of this restriction, a valid BMI could not be computed for $7.2 \%$ of the children. To categorize children as non-overweight (ie, normal or underweight), overweight, or obese, the BMI cutoff points defined by Cole et al were applied. ${ }^{7}$ Mothers and fathers were also asked to indicate separately whether they perceived themselves to have severe overweight (yes/no). Additionally, the questionnaire asked about the mother's country of birth, age, and highest completed education, the season the questionnaire was completed, and alternative lifestyle (yes/no). The highest education completed by the mother was categorized in 3 levels (low, medium, and high), in line with international classification systems. ${ }^{8}$ Low education level comprised elementary school, lower vocational education, and lower general secondary education. Medium education level comprised intermediate vocational education, higher general secondary education, and college-prep. Higher education level comprised higher vocational education and college.

All analyses were performed with SPSS software version 13.0 (Chicago, Illinois). Cases with missing values were excluded. Independent $t$ tests were performed to test sex and weight status differences. Bivariate correlations between intake frequencies and activity durations were calculated with Spearman rank correlations. Interpretation of the correlations was based on Cohen's guidelines: ${ }^{9}$ absolute correlation ( $\mathrm{r}$ ) between 0.1 and 0.3 was considered small; 0.3 to 0.5 was considered medium; and $\geq 0.5$ large. Principal component analysis with oblique rotation was performed to examine behavioral clustering. All variables were standardized, and a scree plot was used to determine the number of components. Items with absolute component loadings $>0.3$ were considered part of the component, in line with earlier research, ${ }^{10}$ although cutoff points in other studies were found to vary between 0.2 and 0.6 . Cluster scores were computed for each child as the sum of all behavioral-item scores multiplied by their corresponding component loadings. ${ }^{5}$ These cluster scores were then used as dependent variables in backward linear regression analyses to examine the relationship between background characteristics and cluster scores. The independent variables were sex, weight status of the child, parental obesity and alternative lifestyle, maternal education, age, and country of birth, and season of questionnaire completion. In all analyses, $P$ values $<.05$ were considered to be statistically significant.

\section{Results}

Of the 2392 children with complete weight and height data, $207(8.7 \%)$ were overweight, and $36(1.5 \%)$ were obese. A 
Table I. Average activity behavior duration of 2-year-old children in the KOALA Birth Cohort Study $\left(\mathbf{n}=2471^{\star}\right)$

\begin{tabular}{lccccc}
\hline & $\mathbf{0}$ minutes/day (\%) & $\mathbf{1 - 1 4}$ minutes/day (\%) & $\mathbf{1 5 - 5 9}$ minutes/day (\%) & $\mathbf{6 0 - 1 1 9}$ minutes/day (\%) & $\geq 120$ minutes/day (\%) \\
\hline Playing outside & 1.5 & 6.2 & 35.3 & 38.3 & 18.7 \\
TV viewing & 8.1 & 33.8 & 49.1 & 7.9 & 1.1 \\
Computer use & 95.5 & 4.0 & 0.5 & 0.0 & 0.0 \\
\hline
\end{tabular}

${ }^{*} n$ deviates from total sample size because of missing values.

total of $5.2 \%$ of the mothers and $2.8 \%$ of the fathers reported being obese. Furthermore, $2.5 \%$ of the children of obese mothers were obese themselves, as compared with $1.4 \%$ of the children with a non-obese mother. For the fathers, $1.6 \%$ of the obese and $1.4 \%$ of the non-obese fathers had an obese child.

On average, the children played outside for approximately 1 hour per day (Table I). Boys played outside significantly longer than girls $(P<.05), 69$ minutes per day $(\mathrm{SD}, 39)$ for the boys compared with 66 minutes $(\mathrm{SD}, 40)$ for the girls. Only $4.5 \%$ of the children used computers. The average computer time for the children who did use them was 11 minutes per day (SD, 12). For dietary intake (Table II), overweight or obese children consumed significantly fewer snacks on average than non-overweight children: $1.5(\mathrm{SD}, 1.0)$ versus 1.6 snacks $(\mathrm{SD}, 0.8)$ per day respectively $(P<.05)$. Light soft drinks were consumed less than once per week on average, with only $16.6 \%$ of the children consuming them. With the exception of playing outside and snack intake, there were no significant sex or weight status differences.

The correlations between activity behaviors and food intake behaviors were small (absolute $\mathrm{r}$ between 0.1 and 0.3 ), except for the medium correlation between snacking and sugar-sweetened drink intake $(r=0.37$; Table III). Behaviors expected to contribute to a positive energy balance (such as TV viewing, snacking, and sugared drink intake) were positively correlated and inversely related with healthy behaviors, such as playing outside and eating fresh fruit, vegetables, and brown bread.

Principal component analyses revealed 2 clusters (Table IV). The first cluster included TV viewing, computer use, eating snacks, and drinking sugar-sweetened and light drinks ("sed-

Table II. Average dietary intake frequencies of 2-yearold children in the KOALA Birth Cohort Study $\left(\mathbf{n}=2373^{\star}\right)$

\begin{tabular}{lcccc}
\hline & $\begin{array}{c}<\text { time/ } \\
\text { day (\%) }\end{array}$ & $\begin{array}{c}\text { 1-2 times/ } \\
\text { day (\%) }\end{array}$ & $\begin{array}{c}\text { 2-3 times/ } \\
\text { day (\%) }\end{array}$ & $\begin{array}{c}\geq \text { 3 times/ } \\
\text { day (\%) }\end{array}$ \\
\hline Snacks & 26.1 & 44.1 & 20.4 & 9.4 \\
Sugar-sweetened drinks & 70.1 & 13.1 & 10.4 & 6.4 \\
Light soft drinks & 98.3 & 1.0 & 0.5 & 0.2 \\
Vegetables & 40.4 & 54.6 & 4.2 & 0.8 \\
Fresh fruit & 23.9 & 53.1 & 21.3 & 1.7 \\
Brown bread & 10.6 & 20.0 & 66.8 & 2.6 \\
White bread & 94.6 & 3.3 & 2.1 & 0.0 \\
\hline
\end{tabular}

${ }^{*} \mathrm{n}$ deviates from total sample size because of missing values. entary-snacking cluster"). The second cluster comprised vegetable, fresh fruit, and brown bread consumption and rare white bread consumption ("fiber cluster"). These 2 clusters were inversely correlated $(r=-0.14)$ and explained $30.3 \%$ of the variance in the original items.

Regression analyses on the cluster scores showed that higher sedentary-snacking cluster scores were predicted by maternal obesity (standardized regression coefficient $\beta=$ $0.06 ; P<.01)$ and by low and medium education levels ( $\beta=0.13 ; P<.001$ and $\beta=0.16 ; P<.001$, respectively, compared with high education level). For the fiber cluster, low $(\beta=-0.17 ; P<.001)$ and medium $(\beta=-0.15 ; P<.001)$ maternal education levels compared with high education level were significantly inversely related to cluster score. Reported regression coefficients were corrected for potential confounding influences of alternative lifestyle and season of questionnaire completion. Sex, child's and father's weight status, and mother's country of birth and age were not significantly related to either cluster.

\section{Discussion}

Two interesting behavioral clusters emerged in this study. The first, a sedentary-snacking cluster, comprised sedentary behavior and unhealthy dietary intake behaviors, such as snacking and soft drink consumption. Children scoring high in this cluster are more likely to develop obesity. ${ }^{11}$ There are several proposed mechanisms to explain the clustering of sedentary behaviors and unhealthy food intake, including the stimulating influence of TV snack commercials, ${ }^{12}$ provision of a context during sedentary activities that promotes passive snacking or overeating, ${ }^{13}$ and the distracting influence of TV watching while eating, which disrupts habituation to food cues (eg, satiety). ${ }^{14}$ Second, we identified a fiber cluster characterized by eating fresh fruit, vegetables, and brown bread more often and white bread less often. There is convincing evidence for the protective role of dietary fiber against the development of overweight and obesity. ${ }^{11}$

Light soft drinks are calorie free and could therefore be expected to cluster with healthy behaviors. Instead, they were associated with sedentary behaviors and unhealthy dietary patterns. This pattern is consistent with earlier findings in adolescents, ${ }^{15}$ and may be explained by parents restricting light soft drink consumption because they consider it unhealthy because of potentially negative effects in other health areas. 
Table III. Correlations between activity behavior and dietary intake $\left(n=2276^{*}\right)$

\begin{tabular}{|c|c|c|c|c|c|c|c|c|c|}
\hline & TV & Computer & Snacks & Sugar-sweetened drinks & Light soft drinks & Vegetables & Fresh fruit & Brown bread & White bread \\
\hline \multicolumn{10}{|l|}{ Activity behavior } \\
\hline Playing outside & -0.10 & & & & & 0.10 & & & \\
\hline TV & - & & 0.22 & 0.16 & & -0.15 & -0.11 & & \\
\hline Computer & & - & & & & & & & \\
\hline \multicolumn{10}{|l|}{ Dietary intake } \\
\hline Snacks & & & - & 0.37 & 0.13 & & & & 0.12 \\
\hline Sugar-sweetened drinks & & & & - & 0.17 & & -0.10 & & 0.16 \\
\hline Light soft drinks & & & & & - & & & & 0.13 \\
\hline Vegetables & & & & & & - & 0.28 & & \\
\hline Fresh fruit & & & & & & & - & 0.19 & -0.12 \\
\hline Brown bread & & & & & & & & - & -0.23 \\
\hline
\end{tabular}

Results of Spearman correlation analyses. Only correlations with small effect size (absolute correlation $>0.1$ ) or larger are reported; all depicted results are significant at $P \leq .01$.

${ }^{*} \mathrm{n}$ deviates from total sample size because of missing values.

Parents play a crucial role in the lives of young children. They decide almost every aspect of the toddler's life, including factors influencing EBRBs and weight gain. Parents control the availability of and exposure to foods, determine daily activity patterns, are role models, practice certain parenting styles, and can provide support and structure for their child. ${ }^{16,17}$ When trying to change EBRBs and prevent excessive weight gain in young children, it is therefore necessary to target parents more intensively than is current practice in the obesity prevention field. In this study, maternal education level was found to significantly influence both cluster scores, with a lower education level being related to EBRBs that could predict obesity risk. This is in line with earlier research. ${ }^{5,18}$ Furthermore, maternal obesity was associated with a high sedentary-snack cluster score in this study. These findings stress the importance of parents in the life of young children and indicate that interventions should focus on these high risk groups. In contrast to mother's obesity, father's obesity was not related to these 2 clusters, possibly reflecting the traditionally greater role mothers play in rearing young children.

Table IV. Component loadings of principal component analysis on activity behavior and dietary intake

$\left(\mathrm{n}=2097^{\star}\right)$

\begin{tabular}{lrr} 
& \multicolumn{2}{c}{ Cluster } \\
\cline { 2 - 3 } & \multicolumn{1}{c}{$\mathbf{1}$} \\
\hline Activity behavior & & $\mathbf{2}$ \\
Playing outside & -0.015 & 0.151 \\
TV & 0.479 & -0.135 \\
Computer & 0.326 & 0.122 \\
Dietary intake & & \\
Snacks & 0.733 & -0.027 \\
Sugar-sweetened drinks & 0.669 & -0.009 \\
Light soft drinks & 0.361 & -0.097 \\
Vegetables & -0.106 & 0.468 \\
Fresh fruit & -0.094 & 0.532 \\
Brown bread & 0.299 & 0.736 \\
White bread & 0.017 & -0.606 \\
\hline
\end{tabular}

Results of oblique principal component analysis.

*n deviates from total sample size because of missing values.
Contrary to expectations, no association was found between the child's weight status and cluster scores. This could be because of the cross-sectional nature of the data; it would therefore be interesting to re-examine the effect of the cluster scores on weight status at a later age. However, it also indicates that, at this age, the deleterious effects of unhealthy behaviors have not yet manifested in the child's weight status. This implies a window of opportunity for early prevention. The slightly lower snack intake found in overweight and obese children could be an indication of adaptive behavior of the parents, with parents already correcting the diet of their children because of emerging overweight of the child. This seems plausible because the children were examined physically (including weight and height measurements) at the infant welfare center just before the parents filled out the questionnaire.

In interpreting these results, some limitations should be taken into account. Our study population was not a representative sample of the Dutch population. Almost half the mothers had a high education level, as opposed to onethird of the 25- to 45-year-old women in the Netherlands. ${ }^{19}$ All data, including weight and height, were reported by parents and therefore could be biased. However, the questionnaires were completed shortly after visits to infant welfare centers, and parents were asked to take down the results of the anthropometric measurements taken there. Overweight and obesity prevalence in the study population were similar to other Dutch prevalence figures. ${ }^{20}$ However, parental reports of their child's behaviors may have been subject to bias, and results on children attending daycare (58.5\%) might be influenced, because of less parental awareness of the child's EBRBs during daycare. Furthermore, the food frequency questions and activity measures were not validated, and not all food intake and activity behaviors were taken into account (eg, active indoor playing), although the EBRBs examined here are commonly considered to be the most important risk factors for child and adolescent obesity. ${ }^{11,21}$

Despite these limitations, this study provides insights and expands the evidence base of EBRB clustering in toddlers. Clustering across dietary intake and activity behavior has 
been demonstrated in 2-year-old children. The existence of behavioral clusters at this young age calls for an integrated prevention approach in which physical activity and dietary intake are addressed simultaneously.

Submitted for publication Nov 19, 2008; last revision received Jan 15, 2009; accepted Feb 13, 2009.

Reprint requests: Jessica Gubbels, MSc, Maastricht University Medical Centre, Department of Health Promotion, PO Box 616, 6200 MD Maastricht, The Netherlands. E-mail: Jessica.Gubbels@GVO.unimaas.nl.

\section{References}

1. Schuit AJ, van Loon AJ, Tijhuis M, Ocke M. Clustering of lifestyle risk factors in a general adult population. Prev Med 2002;35:219-24.

2. DuRant RH, Baranowski T, Johnson M, Thompson WO. The relationship among television watching, physical activity, and body composition of young children. Pediatrics 1994;94:449-55.

3. Knol LL, Haughton B, Fitzhugh EC. Dietary patterns of young, lowincome US children. J Am Diet Assoc 2005;105:1765-73.

4. Northstone K, Emmett P. Multivariate analysis of diet in children at four and seven years of age and associations with socio-demographic characteristics. Eur J Clin Nutr 2005;59:751-60.

5. Lioret S, Touvier M, Lafay L, Volatier JL, Maire B. Dietary and physical activity patterns in French children are related to overweight and socioeconomic status. J Nutr 2008;138:101-7.

6. Kummeling I, Thijs C, Penders J, Snijders BE, Stelma F, Reimerink J, et al. Etiology of atopy in infancy: the KOALA Birth Cohort Study. Pediatr Allergy Immunol 2005;16:679-84.

7. Cole TJ, Bellizzi MC, Flegal KM, Dietz WH. Establishing a standard definition for child overweight and obesity worldwide: international survey. BMJ 2000;320:1240-3.

8. Eurostat. Task Force on Core Social Variables. Final report. Luxembourg: European Communitees; 2007.
9. Cohen J. Statistical power analysis for the behavioral sciences. New York: Hillsdale, Erlbaum; 1988.

10. Field A. Discovering statistics using SPSS. London, Thousand Oaks, New Delhi: Sage Publications; 2005.

11. WHO/FAO Expert Consultation. Joint WHO/FAO Expert Consultation: diet, nutrition and the prevention of chronic diseases. WHO Technical Report Series. Geneva: WHO; 2003.

12. HalfordCBoylandJHugheGOliveirdPDoveyTMBeyond-brandffectofelevision(TV)foodadvertisements/commercialsncaloriantakendoodhoicœ6-7year-oldhildrenAppetite007;49:263-7.

13. Coon KA, Goldberg J, Rogers BL, Tucker KL. Relationships between use of television during meals and children's food consumption patterns. Pediatrics 2001;107:E7.

14. Temple JL, Giacomelli AM, Kent KM, Roemmich JN, Epstein LH. Television watching increases motivated responding for food and energy intake in children. Am J Clin Nutr 2007;85:355-61.

15. Striegel-Moore RH, Thompson D, Affenito SG, Franko DL, Obarzanek E, Barton BA, et al. Correlates of beverage intake in adolescent girls: the National Heart, Lung, and Blood Institute Growth and Health Study. J Pediatr 2006;148:183-7.

16. Golan M, Crow S. Parents are key players in the prevention and treatment of weight-related problems. Nutr Rev 2004;62:39-50.

17. Ebbeling CB, Pawlak DB, Ludwig DS. Childhood obesity: public-health crisis, common sense cure. Lancet 2002;360:473-82.

18. Aranceta J, Perez-Rodrigo C, Ribas L, Serra-Majem L. Sociodemographic and lifestyle determinants of food patterns in Spanish children and adolescents: the enKid study. Eur J Clin Nutr 2003;57:S40-4.

19. Centraal Bureau voor de Statistiek. Beroepsbevolking; geslacht en leeftijd. Voorburg/Heerlen: CBS; 2005.

20. Van den Hurk $K$, van Dommelen $P$, van Buuren S, Verkerk PH, Hirasing RA. Prevalence of overweight and obesity in the Netherlands in 2003 compared to 1980 and 1997. Arch Dis Child 2007; 92:992-5.

21. Rennie KL, Johnson L, Jebb SA. Behavioural determinants of obesity. Best Pract Res Clin Endocrinol Metab 2005;19:343-58. 